\title{
Reclassification of Geobacillus pallidus (Scholz et al. 1988) Banat et al. 2004 as Aeribacillus pallidus gen. nov., comb. nov.
}

\author{
David Miñana-Galbis, ${ }^{1}$ Dora L. Pinzón, ${ }^{2}$ J. Gaspar Lorén, ${ }^{1}$ \\ Àngels Manresa ${ }^{1}$ and Rosa M. Oliart-Ros ${ }^{2}$ \\ ${ }^{1}$ Departament de Microbiologia i Parasitologia Sanitàries, Facultat de Farmàcia, Universitat de \\ Barcelona, Av. Joan XXIII s/n, 08028 Barcelona, Spain \\ ${ }^{2}$ Unidad de Investigación y Desarrollo en Alimentos, Instituto Tecnológico de Veracruz, Av. Miguel A. \\ de Quevedo 2779, 91860 Veracruz, Ver., Mexico
}

Correspondence

David Miñana-Galbis

davidminyana@ub.edu

\begin{abstract}
Although Anoxybacillus and Geobacillus, two genera of thermophilic bacteria close to the genus Bacillus, have only been described recently, the number of species in these genera has increased rapidly. Four thermophilic, lipolytic strains (DR01, DR02, DR03 and DR04) isolated from a hot spring in Veracruz (Mexico), which could not be identified phenotypically, were subjected to $16 \mathrm{~S}$ rRNA gene sequence analysis. Three strains were identified as belonging to the genus Anoxybacillus, but strain DR03 was identified as Geobacillus pallidus. This result led us to perform a phylogenetic analysis of the genera Anoxybacillus and Geobacillus based on 16S rRNA gene sequences from all the type strains of these genera. Phylogenetic trees showed three major clusters, Anoxybacillus-Geobacillus tepidamans, Geobacillus sensu stricto and Geobacillus pallidus, while the 16S rRNA gene sequences of G. pallidus (DR03 and the type strain) showed low similarity to sequences of Anoxybacillus (92.5-95.1\%) and Geobacillus (92.8-94.5\%) species, as well as to Bacillus subtilis (92.2-92.4\%). In addition, G. pallidus could be differentiated from Anoxybacillus and Geobacillus on the basis of DNA G $+\mathrm{C}$ content and fatty acid and polar lipid profiles. From these results, it is proposed that Geobacillus pallidus should be classified in a novel genus, for which we propose the name Aeribacillus, as Aeribacillus pallidus gen. nov., comb. nov. The type strain of Aeribacillus pallidus is $\mathrm{H}_{12}{ }^{\top}$ (=ATCC $51176^{\top}$ $=$ DSM $3670^{\top}=$ LMG $19006^{\top}$ ).
\end{abstract}

The thermophilic bacterial genera Anoxybacillus and Geobacillus were described in the radiation from the Gram-positive genus Bacillus (Pikuta et al., 2000; Nazina et al., 2001). The genus Geobacillus was described for six species belonging to the aerobic thermophilic Bacillus group 5, including Geobacillus stearothermophilus as the type species, and two novel species (Geobacillus subterraneus and Geobacillus uzenensis), based on physiological characteristics, fatty acid composition, DNA-DNA hybridization studies and 16S rRNA gene sequence analysis (Nazina et al., 2001). Members of this genus are Gram-positive, sporeforming rods, neutrophilic, moderately thermophilic and aerobic or facultatively anaerobic. They contain iso- $\mathrm{C}_{15: 0}$,

The GenBank/EMBL/DDBJ accession numbers for the 16S rRNA gene sequences of strains DR01, DR02, DR03 and DR04 are respectively EU621359-EU621362.

A $16 S$ rRNA gene sequence similarity matrix and maximum-likelihood tree, polar lipid profiles and a comparison of $\mathrm{G}+\mathrm{C}$ content and fatty acid profiles of Anoxybacillus and Geobacillus species are available with the online version of this paper. iso- $\mathrm{C}_{16: 0}$ and iso- $\mathrm{C}_{17: 0}$ as the major cellular fatty acids. The $\mathrm{G}+\mathrm{C}$ content of the genomic DNA is $48.2-58 \mathrm{~mol} \%$ and $16 \mathrm{~S}$ rRNA gene sequence analysis of these species results in a very compact phylogenetic cluster, exhibiting internal levels of sequence similarity higher than $96.5 \%$.

To date, 18 Geobacillus species have been described, including 'Geobacillus zalihae' (Rahman et al., 2007), the name of which has not been validly published. This continuing description of novel species has introduced some discrepancies with respect to the original characteristics of the genus. For some species, the $\mathrm{G}+\mathrm{C}$ content of the DNA is below $48 \mathrm{~mol} \%$ and/or the fatty acid profile (when determined) is different from that described for the genus. Moreover, low pairwise 16S rRNA sequence similarity values have been described among Geobacillus species, as in the case of Geobacillus debilis with respect to G. stearothermophilus (93\%) and Geobacillus pallidus (91\%) (Banat et al., 2004).

The genus Anoxybacillus includes Gram-positive, sporeforming rods, alkaliphilic or alkalitolerant, thermophilic 
and aerotolerant or facultative anaerobes. The main fatty acid is iso- $\mathrm{C}_{15: 0}$ and the DNA $\mathrm{G}+\mathrm{C}$ content is 42 $57 \mathrm{~mol} \%$. Sequences of the $16 \mathrm{~S}$ rRNA gene showed at least $96 \%$ similarity between the three Anoxybacillus species that were included in the emended description of the genus (Pikuta et al., 2003). At the time of writing, the genus Anoxybacillus comprises a total of 10 species, including the slightly acidophilic species Anoxybacillus amylolyticus (Poli et al., 2006) and the strict aerobe Anoxybacillus rupiensis (Derekova et al., 2007), two species whose type strains show high 16S rRNA gene sequence similarity to that of Geobacillus tepidamans (97.5 and $96.5 \%$, respectively).

Recently, we isolated four thermophilic, lipolytic strains (DR01, DR02, DR03 and DR04) from a hot spring in Veracruz (Mexico), and these were preliminarily identified as belonging to the genus Anoxybacillus (Pinzón et al., $2007 \mathrm{a}, \mathrm{b}$ ). The authors reported the first characterization of thermostable lipases from Anoxybacillus strains, adding to some Bacillus and Geobacillus strains that have been described previously as thermostable-lipase producers by other authors (Schmidt-Dannert et al., 1994; Castro-Ochoa et al., 2005; Rahman et al., 2007).

In the present study, $16 \mathrm{~S}$ rRNA gene sequences of all four strains were determined as described previously (Miñana-Galbis et al., 2007) in order to confirm their identity. Sequences were about $1500 \mathrm{bp}$ long. Sequences of strains DR01, DR02 and DR04 showed only 1-2 nucleotide differences, as well as a high level of similarity to sequences of Anoxybacillus ayderensis, Anoxybacillus gonensis, Anoxybacillus flavithermus and Anoxybacillus kamchatkensis (>99 \%; Supplementary Table S1, available in IJSEM Online). In contrast, strain DR03 could not be assigned to the genus Anoxybacillus because its 16S rRNA gene sequence was almost identical to that of G. pallidus DSM $3670^{\mathrm{T}}$ (2 nucleotide differences). This unexpected result was confirmed by DNA-DNA hybridization between strain DR03 and G. pallidus LMG $19006^{\mathrm{T}}$, performed by the BCCM/LMG (Belgian Coordinated Collections of Micro-organisms/Laboratorium voor Microbiologie from Universiteit Gent) Identification Service, as described previously (Miñana-Galbis et al., 2007). This analysis revealed $82 \%$ DNA relatedness, and we therefore concluded that strain DR03 belongs to G. pallidus (Wayne et al., 1987).

This result led us to perform a phylogenetic analysis of the genera Anoxybacillus and Geobacillus based on 16S rRNA gene sequences from all the type strains of these genera (taken from GenBank) and from our strains. Sequence alignment and phylogenetic analysis were conducted using MEGA version 4.0 (Kumar et al., 2004; Tamura et al., 2007) except in the case of the maximum-likelihood method, which was performed using PhyML version 3.0 (Guindon \& Gascuel, 2003). Phylogenetic trees with complete- and pairwise-deletion options were reconstructed by maximum-parsimony and neighbour-joining methods. The latter method was performed using different distance estimation models (Jukes-Cantor, Kimura two-parameter and Tamura-Nei). The topological robustness of the phylogenetic trees was evaluated by a bootstrap analysis through 1000 replicates. All the obtained dendrograms showed almost identical topologies. The neighbour-joining tree with the Jukes-Cantor model and the pairwisedeletion option is shown in Fig. 1, while pairwise $16 \mathrm{~S}$ rRNA gene sequence similarities are presented in Supplementary Table S1.

Three major clusters can be observed in Fig. 1. The cluster of the genus Anoxybacillus grouped all Anoxybacillus species, strains DR01, DR02 and DR04 and G. tepidamans with a bootstrap value of $80 \%$. Within this cluster, G. tepidamans was grouped in the same phylogenetic branch as $A$. rupiensis, although this phylogenetic relationship was not confirmed by the maximum-likelihood method (Supplementary Fig. S1). 16S rRNA gene sequence similarities between G. tepidamans and Anoxybacillus species and other Geobacillus species ranged from 94.0 to $98.0 \%$ (29-80 nucleotide differences) and 91.7 to $96.0 \%$ (52-106 nucleotide differences), respectively (Supplementary Table S1). Nevertheless, A. rupiensis and G. tepidamans shared higher sequence similarities with type strains of their respective genera than with those from the other genus (Supplementary Table S1). Further analyses such as housekeeping gene sequencing (Zeigler, 2005) are needed for clarification of the taxonomic and phylogenetic positions of A. rupiensis and G. tepidamans.

In a second cluster, all species of the genus Geobacillus, except for G. tepidamans and G. pallidus, were grouped with a bootstrap value of $92 \%$. G. pallidus strains (the type strain and DR03) were grouped in a third cluster $(100 \%$ bootstrap), constituting an independent phylogenetic line. The 16S rRNA gene sequence similarity between G. pallidus (DR03 and the type strain) and species of the Anoxybacillus and Geobacillus clusters ranged from 92.5 to $95.1 \%$ (72103 nucleotide differences) and 92.8 to $94.5 \%$ (74-108 nucleotide differences), respectively; the range was $92.2-$ $92.4 \%$ with respect to the $16 \mathrm{~S}$ rRNA gene sequence of the Bacillus subtilis type strain, which was included in the phylogenetic analysis as an outgroup (Supplementary Table S1). This result was confirmed by the maximumlikelihood method (Supplementary Fig. S1), suggesting that G. pallidus could represent a new genus in the family Bacillaceae. Although there are no clear-cut recommendations for genus delineation (Gillis et al., 2001), these similarity levels were significantly lower than $96.5 \%$, the value suggested by Nazina et al. (2001) for members of the genus Geobacillus.

Additionally, comparison of DNA G + C content and fatty acid profiles between species belonging to the genera Anoxybacillus and Geobacillus was performed (Supplementary Table S2). The $\mathrm{G}+\mathrm{C}$ content ranged from 42 to $50 \mathrm{~mol} \%$ in the genus Anoxybacillus and from 44 to $58 \mathrm{~mol} \%$ in the genus Geobacillus, except in the case of $G$. pallidus (39-41 mol\%) and G. tepidamans (42-43 mol\%). 


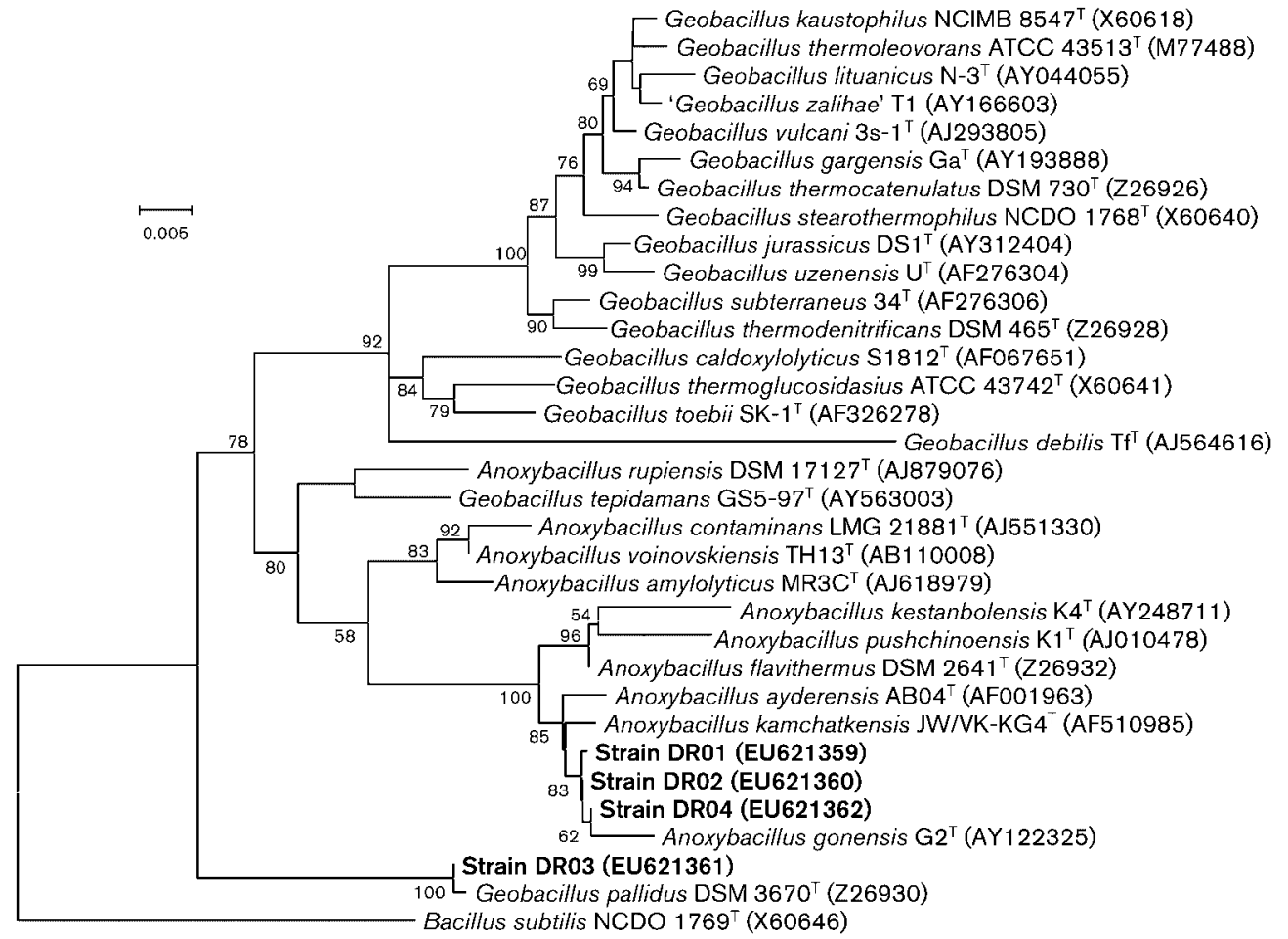

Fig. 1. Consensus neighbour-joining phylogenetic tree (Jukes-Cantor model and pairwise-deletion option) obtained from 33 sequences of the 16S rRNA gene, encompassing all Anoxybacillus and Geobacillus species. GenBank accession numbers are indicated in parentheses. Bar, distance of 0.005 substitutions per nucleotide position as calculated by MEGA. Bootstrap values (>50\%) after 1000 replicates are shown.

The main fatty acid in Anoxybacillus species is iso- $\mathrm{C}_{15: 0}$ $(>38 \%)$, whereas the major cellular fatty acids in Geobacillus are iso- $\mathrm{C}_{15: 0}$, iso- $\mathrm{C}_{16: 0}$ and iso- $\mathrm{C}_{17: 0}$ $(>60 \%)$, except in the case of Geobacillus vulcani $(52.2 \%)$ and G. pallidus $(19.5 \%)$, where the main fatty acid is $\mathrm{C}_{16: 0}(50 \%)$. The fatty acid profile of $G$. pallidus LMG $19006^{\mathrm{T}}$ comprised $\mathrm{C}_{16: 0}(50.0 \%)$, iso- $\mathrm{C}_{16: 0}(9.3 \%)$, $\mathrm{C}_{14: 0}(8.5 \%)$, anteiso- $\mathrm{C}_{17: 0}(6.5 \%)$, iso- $\mathrm{C}_{15: 0}(6.2 \%)$, anteiso- $\mathrm{C}_{15: 0}(4.9 \%)$, iso- $\mathrm{C}_{17: 0}(4.0 \%), \mathrm{C}_{18: 0}(2.1 \%)$, anteiso- $\mathrm{C}_{14: 0}(1.6 \%)$, iso- $\mathrm{C}_{14: 0}(1.6 \%)$ and $\mathrm{C}_{15: 0}(1.2 \%)$ (Scholz et al., 1987).

Polar lipid profiles of Anoxybacillus and Geobacillus species could not be compared because they have not been reported. Because of that, polar lipids of Anoxybacillus pushchinoensis DSM $12423^{\mathrm{T}}$, G. pallidus LMG $19006^{\mathrm{T}}$ and G. stearothermophilus CECT $43^{\mathrm{T}}$ were extracted and analysed as reported previously (Tindall, 1990; Kämpfer et al., 2006; Tindall et al., 2007). Results were compared with Bacillus subtilis ATCC $6051^{\mathrm{T}}$ and standards diphosphatidylglycerol (DPG), phosphatidylglycerol (PG) and phosphatidylethanolamine (PE) (Sigma-Aldrich). The polar lipid profile of the type strain of the type species of the genus Anoxybacillus exhibited DPG, PE, PG and two unknown polar lipids (aminolipid AL1 and polar lipid L1). In contrast, G. pallidus LMG $19006^{\mathrm{T}}$ produced large to moderate amounts of DPG, PG, L1 and four unknown polar lipids (glycolipids GL1 and GL2, glycophospholipid GPL1 and polar lipid L2) and small amounts of three other polar lipids (glycolipids GL3 and GL4 and phospholipid PL1) and lacked PE. The polar lipid composition of the type strain of the type species of the genus Geobacillus was also different from those of the other two type strains, since this strain exhibited large to moderate amounts of DPG, PE, AL1 and an unknown aminophospholipid (APL1) and small amounts of L1 and an unknown aminophospholipid (APL2) and lacked PG (Supplementary Fig. S2).

Therefore, G. pallidus can also be distinguished from Anoxybacillus species and other Geobacillus species by the DNA $G+C$ content and the fatty acid and polar lipid profiles (Table 1).

On the basis of 16S rRNA gene sequence similarities, phylogenetic analyses, DNA G $+C$ contents and cellular fatty acid and polar lipid profiles, we propose that Geobacillus pallidus (Banat et al., 2004) is reclassified as Aeribacillus pallidus gen. nov., comb. nov.

\section{Description of Aeribacillus gen. nov.}

Aeribacillus (Ae.ri.ba.cil'lus. L. n. aer, aeris air; L. masc. n. bacillus a small rod; N.L. masc. n. Aeribacillus aerobic small rod). 
Table 1. Characteristics that distinguish the genus Aeribacillus gen. nov. from the genera Anoxybacillus and Geobacillus

Data were taken from the following studies: Aeribacillus gen. nov., this study and Scholz et al. (1987); Anoxybacillus, this study and Pikuta et al. (2000, 2003); Geobacillus, this study and Nazina et al. (2001). Members of all three genera are thermophilic and have MK-7 as the main isoprenoid quinone. DPG, Diphosphatidylglycerol; PE, phosphatidylethanolamine; PG, phosphatidylglycerol; AL, unknown aminolipid; APL, unknown aminophospholipid; GPL, unknown glycophospholipid; GL, unknown glycolipid; L, unknown polar lipid.

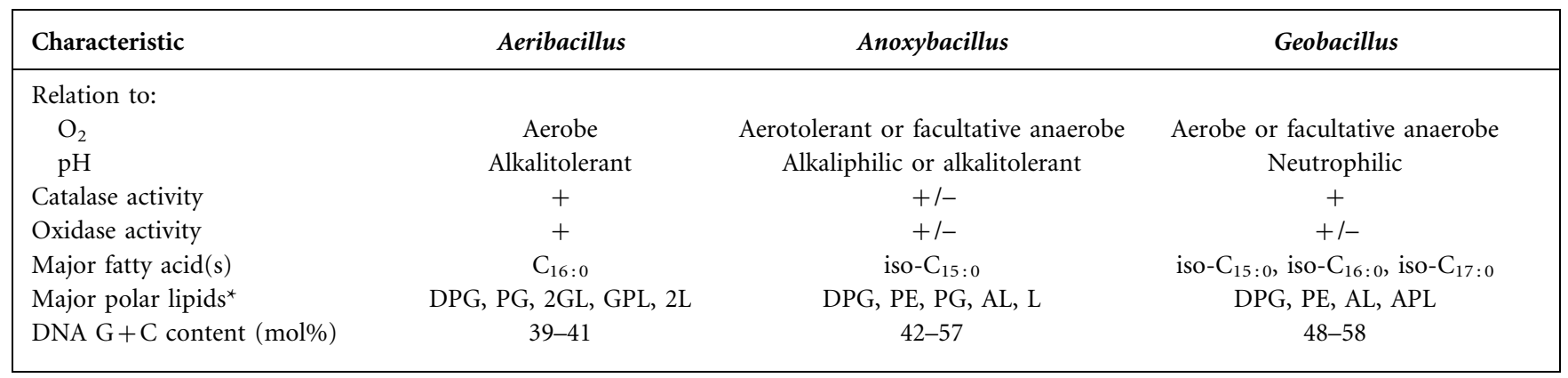

${ }^{*}$ The same aminolipid (AL1) was produced by Anoxybacillus and Geobacillus species. One of the unknown polar lipids (L1) was produced by Aeribacillus, Anoxybacillus and Geobacillus, but the latter genus exhibited only minor amounts.

Cells are aerobic, thermophilic, alkalitolerant, motile, Grampositive rods $(0.8-0.9 \times 2-5 \mu \mathrm{m})$ that occur singly, in pairs or in chains. Ellipsoidal to cylindrical endospores are formed centrally to terminally within slightly swollen sporangia. Catalase- and oxidase-positive. The main menaquinone is MK-7. Predominant polar lipids are diphosphatidylglycerol, phosphatidylglycerol, two unknown glycolipids, an unknown glycophospholipid and two unknown polar lipids. In addition, two other unknown glycolipids and an unknown phospholipid may be present. The main fatty acid is $\mathrm{C}_{16: 0}$ and the fatty acids $\mathrm{C}_{14: 0}, \mathrm{C}_{15: 0}, \mathrm{C}_{18: 0}$, anteiso- $\mathrm{C}_{14: 0}$, anteiso- $\mathrm{C}_{15: 0}$, anteiso- $\mathrm{C}_{17: 0}$, iso- $\mathrm{C}_{14: 0}$, iso- $\mathrm{C}_{15: 0}$, iso- $\mathrm{C}_{16: 0}$ and iso- $\mathrm{C}_{17: 0}$ may be present in amounts less than $10 \%$. The DNA G + C content ranges from 39 to $41 \mathrm{~mol} \%$. The type species is Aeribacillus pallidus.

\section{Description of Aeribacillus pallidus comb. nov.}

Aeribacillus pallidus (pal'li.dus. L. masc. adj. pallidus pale, referring to the pale colony colour).

Basonym: Bacillus pallidus Scholz et al. 1988.

Homotypic synonym: Geobacillus pallidus (Scholz et al. 1988) Banat et al. 2004.

In addition to the description given for Bacillus pallidus by Scholz et al. (1987), the species exhibits the properties listed in the genus description above. The type strain is $\mathrm{H} 12^{\mathrm{T}}$ (=ATCC $51176^{\mathrm{T}}=\mathrm{DSM} 3670^{\mathrm{T}}=\mathrm{LMG} 19006^{\mathrm{T}}$ ).

\section{Acknowledgements}

We thank the Serveis Cientificotècnics of the Universitat de Barcelona (Unitat de Genòmica) for technical assistance and Robin Rycroft for correcting the manuscript. This work has been supported by projects CGL2004-03385/BOS and CTQ2007-60749/PPQ from the Ministerio de Educación y Ciencia, Spain, and 362.06-P from the DGEST-SEP, Mexico.

\section{References}

Banat, I. M., Marchant, R. \& Rahman, T. J. (2004). Geobacillus debilis sp. nov., a novel obligately thermophilic bacterium isolated from a cool soil environment, and reassignment of Bacillus pallidus to Geobacillus pallidus comb. nov. Int J Syst Evol Microbiol 54, 21972201.

Castro-Ochoa, L. D., Rodríguez-Gómez, C., Valerio-Alfaro, G. \& Ros, R. O. (2005). Screening, purification and characterization of the thermoalkalophilic lipase produced by Bacillus thermoleovorans CCR11. Enzyme Microb Technol 37, 648-654.

Derekova, A., Sjøholm, C., Mandeva, R. \& Kambourova, M. (2007). Anoxybacillus rupiensis sp. nov., a novel thermophilic bacterium isolated from Rupi basin (Bulgaria). Extremophiles 11, 577-583.

Gillis, M., Vandamme, P., De Vos, P., Swings, J. \& Kersters, K. (2001). Polyphasic taxonomy. In Bergey's Manual of Systematic Bacteriology, 2nd edn, vol. 1, pp. 43-48. Edited by G. M. Garrity, D. R. Boone \& R. W. Castenholz. New York: Springer.

Guindon, S. \& Gascuel, O. (2003). A simple, fast, and accurate algorithm to estimate large phylogenies by maximum likelihood. Syst Biol 52, 696-704.

Kämpfer, P., Rosselló-Mora, R., Falsen, E., Busse, H.-J. \& Tindall, B. J. (2006). Cohnella thermotolerans gen. nov., sp. nov., and classification of 'Paenibacillus hongkongensis' as Cohnella hongkongensis sp. nov. Int J Syst Evol Microbiol 56, 781-786.

Kumar, S., Tamura, K. \& Nei, M. (2004). MEGA3: integrated software for molecular evolutionary genetics analysis and sequence alignment. Brief Bioinform 5, 150-163.

Miñana-Galbis, D., Farfán, M., Fusté, M. C. \& Lorén, J. G. (2007). Aeromonas bivalvium sp. nov., isolated from bivalve molluscs. Int $J$ Syst Evol Microbiol 57, 582-587.

Nazina, T. N., Tourova, T. P., Poltaraus, A. B., Novikova, E. V., Grigoryan, A. A., Ivanova, A. E., Lysenko, A. M., Petrunyaka, V. V., Osipov, G. A. \& other authors (2001). Taxonomic study of aerobic thermophilic bacilli: descriptions of Geobacillus subterraneus gen. nov., sp. nov. and Geobacillus uzenensis sp. nov. from petroleum reservoirs and transfer of Bacillus stearothermophilus, Bacillus thermocatenulatus, Bacillus thermoleovorans, Bacillus kaustophilus, Bacillus thermoglucosidasius and Bacillus thermodenitrificans to Geobacillus as the new combinations G. stearothermophilus, $G$. 
thermocatenulatus, G. thermoleovorans, G. kaustophilus, G. thermoglucosidasius and G. thermodenitrificans. Int J Syst Evol Microbiol 51, 433-446.

Nazina, T. N., Lebedeva, E. V., Poltaraus, A. B., Tourova, T. P., Grigoryan, A. A., Sokolova, D. S., Lysenko, A. M. \& Osipov, G. A. (2004). Geobacillus gargensis sp. nov., a novel thermophile from a hot spring, and the reclassification of Bacillus vulcani as Geobacillus vulcani comb. nov. Int J Syst Evol Microbiol 54, 2019-2024.

Nazina, T. N., Sokolova, D. S., Grigoryan, A. A., Shestakova, N. M., Mikhailova, E. M., Poltaraus, A. B., Tourova, T. P., Lysenko, A. M., Osipov, G. A. \& Belyaev, S. S. (2005). Geobacillus jurassicus sp. nov., a new thermophilic bacterium isolated from a high-temperature petroleum reservoir, and the validation of the Geobacillus species. Syst Appl Microbiol 28, 43-53.

Pikuta, E., Lysenko, A., Chuvilskaya, N., Mendrock, U., Hippe, H., Suzina, N., Nikitin, D., Osipov, G. \& Laurinavichius, K. (2000). Anoxybacillus pushchinensis gen. nov., sp. nov., a novel anaerobic, alkaliphilic, moderately thermophilic bacterium from manure, and description of Anoxybacillus flavithermus comb. nov. Int J Syst Evol Microbiol 50, 2109-2117.

Pikuta, E., Cleland, D. \& Tang, J. (2003). Aerobic growth of Anoxybacillus pushchinoensis $\mathrm{K}^{\mathrm{T}}$ : emended descriptions of $A$. pushchinoensis and the genus Anoxybacillus. Int J Syst Evol Microbiol 53, 1561-1562.

Pinzón, D., Miñana, D., Manresa, A., Valerio, G., Garcia, H. \& OliartRos, R. (2007a). Isolation of new thermophilic lipases from Veracruz's hot springs. In Abstracts of the International Conference on Enzyme Technology "Relatenz 2007", 20-23 June 2007, Varadero, Cuba.

Pinzón, D., Miñana, D., García, H., Valerio, G. \& Oliart, R. (2007b). Obtención de lipasas a partir de ambientes termales de Veracruz. In Abstracts of the XII Congreso Nacional de Biotecnología y Bioingeniería, 25-29 June 2007, Morelia, Mexico. Poster CIV-122. León, Guanajuato, Mexico: IV Encuentro 'Participación de la Mujer en la Ciencia' (in Spanish).
Poli, A., Esposito, E., Lama, L., Orlando, P., Nicolaus, G., de Appolonia, F., Gambacorta, A. \& Nicolaus, B. (2006). Anoxybacillus amylolyticus sp. nov., a thermophilic amylase producing bacterium isolated from Mount Rittmann (Antarctica). Syst Appl Microbiol 29, 300-307.

Rahman, R. N. Z. R. A., Leow, T. C., Salleh, A. B. \& Basri, M. (2007). Geobacillus zalihae sp. nov., a thermophilic lipolytic bacterium isolated from palm oil mill effluent in Malaysia. BMC Microbiol 7, 77.

Schmidt-Dannert, C., Sztajer, H., Stöcklein, W., Menge, U. \& Schmid, R. D. (1994). Screening, purification and properties of a thermophilic lipase from Bacillus thermocatenulatus. Biochim Biophys Acta 1214, 43-53.

Scholz, T., Demharter, W., Hensel, R. \& Kandler, O. (1987). Bacillus pallidus sp. nov., a new thermophilic species from sewage. Syst Appl Microbiol 9, 91-96.

Tamura, K., Dudley, J., Nei, M. \& Kumar, S. (2007). MEGA4: molecular evolutionary genetics analysis (MEGA) software version 4.0. Mol Biol Evol 24, 1596-1599.

Tindall, B. J. (1990). Lipid composition of Halobacterium lacusprofundi. FEMS Microbiol Lett 66, 199-202.

Tindall, B. J., Sikorski, J., Smibert, R. A. \& Krieg, N. R. (2007). Phenotypic characterization and the principles of comparative systematics. In Methods for General and Molecular Bacteriology, pp. 330-393. Edited by C. A. Reddy, T. J. Beveridge, T. A. Breznak, G. A. Marzluf, T. M. Schmidt \& L. R. Snyder. Washington, DC: American Society for Microbiology.

Wayne, L. G., Brenner, D. J., Colwell, R. R., Grimont, P. A. D., Kandler, O., Krichevsky, M. I., Moore, L. H., Moore, W. E. C., Murray, R. G. E. \& other authors (1987). International Committee on Systematic Bacteriology. Report of the ad hoc committee on reconciliation of approaches to bacterial systematics. Int J Syst Bacteriol 37, 463-464.

Zeigler, D. R. (2005). Application of a recN sequence similarity analysis to the identification of species within the bacterial genus Geobacillus. Int J Syst Evol Microbiol 55, 1171-1179. 